\title{
The Application of Piezocone Penetration Test (CPTU) in Water Area Hydrogeological Investigation
}

\author{
Xueying $\mathrm{Gu}^{1 *}$, Yukun Jiang ${ }^{2}$ and Lihong Zhou ${ }^{2}$ \\ ${ }^{1}$ School of Civil and Traffic Engineering, Shanghai Urban Construction Vocational College, Shanghai, 200438, China \\ ${ }^{2}$ East China Electric Power Design Institute Co., Ltd., Shanghai, 200331, China
}

\begin{abstract}
Piezocone penetration test device imported from the Netherlands was used to conduct pore pressure dissipation tests at 4 measuring points in 2 holes in the water area of Sutong GIL utility tunnel project. After dissipation, stable pore pressure was used to analyse groundwater pressure and further obtain the height of groundwater head. This method provides a successful solution for in-situ stratification testing of groundwater parameters in water area engineering, and provides reliable hydrologic parameters such as groundwater pressure for structure design and construction.
\end{abstract}

\section{Introduction}

In the past, the hydrogeological parameters of water area engineering were obtained mainly as follows: (1) the permeability coefficient was obtained by permeability test of drilling sampling; (2) the mixed water level of each aquifer was measured by drilling hole; (3) combined with the pumping test data of the surrounding land area, the water area stratum parameters are compared and analysed.

According to the Code for Investigation of Geotechnical Engineering [1], water stop measures should be taken to separate the measured aquifer from other aquifers when the water level measurement of multi-layer aquifer which has an impact on the engineering is carried out. In practice, it is difficult to guarantee the water stop measures effectively, the mixed water level is often obtained, which may lead to the risk of misjudgement on the stability of foundation pit against inrush[2].There is no engineering case or literature data of in-situ stratified testing of groundwater parameters. Hence, the CPTU technology is used to provide a solution to the engineering problems.

Since it was introduced into China in 1985, CPTU technology has been developed rapidly in large-scale projects in the fields of highway, railway, airport and electric power. It is mainly used for stratum division, determination of pile foundation parameters, consolidation coefficient, shear strength parameters, liquefaction discrimination, etc. [3 6]. However, the application of CPTU in hydrogeological investigation is rarely studied.

In this paper, based on Sutong GIL utility tunnel project, using the pore pressure dissipation function of CPTU, the water head of bottom aquifer of the Yangtze River is measured and compared.

\section{Hydrogeological conditions}

Sutong GIL utility tunnel project is the first Ultra-high voltage (UHV) river crossing tunnel project in the world. It crosses the Yangtze River about $1 \mathrm{~km}$ upstream of Sutong Yangtze river bridge. Shield method is adopted for the tunnel with a length of $5468.5 \mathrm{~m}$. The outer diameter of the structure is $11.6 \mathrm{~m}$, the bottom elevation is $-74.83 \mathrm{~m}$, and the water pressure is estimated to be $0.8 \mathrm{MPa}$ from the river surface. The project is the deepest buried pipe gallery project with the highest water pressure in China.

The basic stratum information of water area of the project is shown in Table 1. The shallow groundwater of the project site belongs to phreatic water, and the phreatic aquifer mainly occurs in the filling, cohesive soil and sandy soil in the shallow stratum, among which the silty sand layer (3) 2 belongs to the corresponding aquifer with good water permeability. During the survey, the measured buried depth of groundwater level (mixed water) is $0.90 \mathrm{~m} \sim 1.40 \mathrm{~m}$.

(4) 2 Silt is a micro confined aquifer with relatively good permeability. The horizontal permeability coefficient is $1.2 \times 10^{-4} \mathrm{~cm} / \mathrm{s} \sim 2.3 \times 10^{-4} \mathrm{~cm} / \mathrm{s}$, and the vertical permeability coefficient is $3.3 \times 10^{-5} \mathrm{~cm} / \mathrm{s} \sim 1.3 \times 10^{-4} \mathrm{~cm} / \mathrm{s}$. (5) 1 silty fine sand $\sim$ (8) 1 medium coarse sand are confined water aquifers, which are good aquifers with strong water abundance and high permeability. The horizontal permeability coefficient measured by laboratory permeability test is $1.9 \times 10^{-4} \mathrm{~cm} / \mathrm{s} \sim 2.9 \times 10^{-3} \mathrm{~cm} / \mathrm{s}$, and the vertical permeability coefficient is $5.5 \times 10^{-}$ ${ }^{4} \mathrm{~cm} / \mathrm{s} \sim 2.9 \times 10^{-3} \mathrm{~cm} / \mathrm{s}$. 
Table1. Basic stratum information of water area of the project

\begin{tabular}{|c|c|c|}
\hline Stratum name and number & Average layer thickness $(\mathrm{m})$ & Aquifer Division \\
\hline (1) 1 Filling & 1.16 & - \\
\hline (2) Silty clay & 1.95 & - \\
\hline (3) 1 Muddy silty clay & 3.15 & - \\
\hline (3) ${ }_{2}$ Silt & 4.59 & Phreatic aquifer \\
\hline (3) 3 Muddy silty clay & 3.75 & - \\
\hline (3) 4 Interbedding of silty clay and silt & 2.15 & - \\
\hline (3) 5 Muddy silty clay & 5.29 & - \\
\hline (3) 6 Silty clay & 5.53 & - \\
\hline (4) 1 Silty clay mixed with silt & 3.89 & - \\
\hline (4) ${ }_{2}$ Silt & 16.21 & Confined aquifer \\
\hline (5) 1 Silty fine sand & 5.20 & Confined aquifer \\
\hline (5) 2 Fine sand & 14.82 & Confined aquifer \\
\hline (6) 1 Medium coarse sand & Undiscovered & Confined aquifer \\
\hline
\end{tabular}

\section{CPTU test in Yangtze River}

As shown in Figure 1, CPTU is equipped with a permeable filter and a sensing element in the cone probe of conventional double bridge cone penetration test, for measuring pore water pressure. The change of pore water pressure can be recorded synchronously during the penetration of the probe, and the dissipation process of pore water pressure can be monitored at a specified depth. In this paper, the I-CFXYP20-15 pore pressure probe imported from Holland is used, with a length of $482 \mathrm{~mm}$ and a cross-sectional area of $15 \mathrm{~cm}^{2}$. The permeable filter is located on the conical shoulder. The measuring range of the probe is $75 \mathrm{MPa}$, side friction $1 \mathrm{MPa}$, inclinometer $20^{\circ}$, and pore pressure $2 \mathrm{MPa}$.

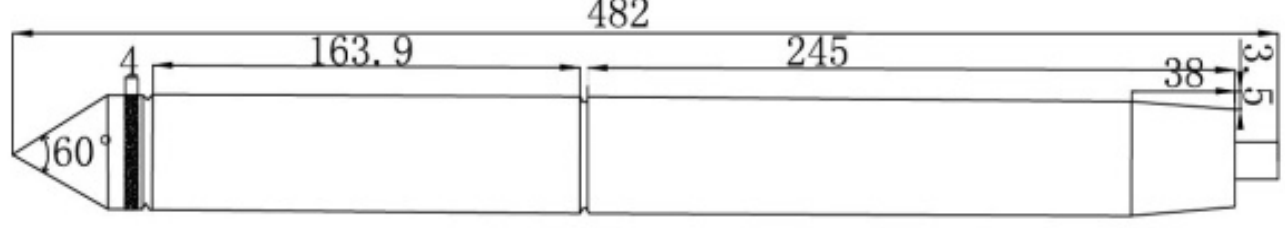

Fig 1. Structure of borehole pressure probe (units: $\mathrm{mm}$ ).

Vacuum saturation before the use of pore pressure probe is very important. Silicone oil saturation is used in this test for about $12 \mathrm{~h}$. The saturation process is shown in Figure 2. The test is carried out on a shipboard working platform. The reaction force is provided by the self weight of the hull. After fixing the hole in the designated coordinates by 6 anchors, the casing is laid to protect the probe rod in the suspension section.

The following test steps are as follows: connect the probe with the probe rod, the cone head shall be placed in the protective sleeve, and it is strictly forbidden to contact the air $\rightarrow$ penetrate the probe through the casing $\rightarrow$ penetrate the probe at the speed of $1.2 \mathrm{~m} / \mathrm{min}$ and record the data $\rightarrow$ stop the penetration to the predetermined depth of the dissipation test and start the dissipation mode $\rightarrow$ the penetration is continued to the final hole depth after the dissipation test is completed $\rightarrow$ the probe rod is lifted. The field test photos are shown in Figure 3.

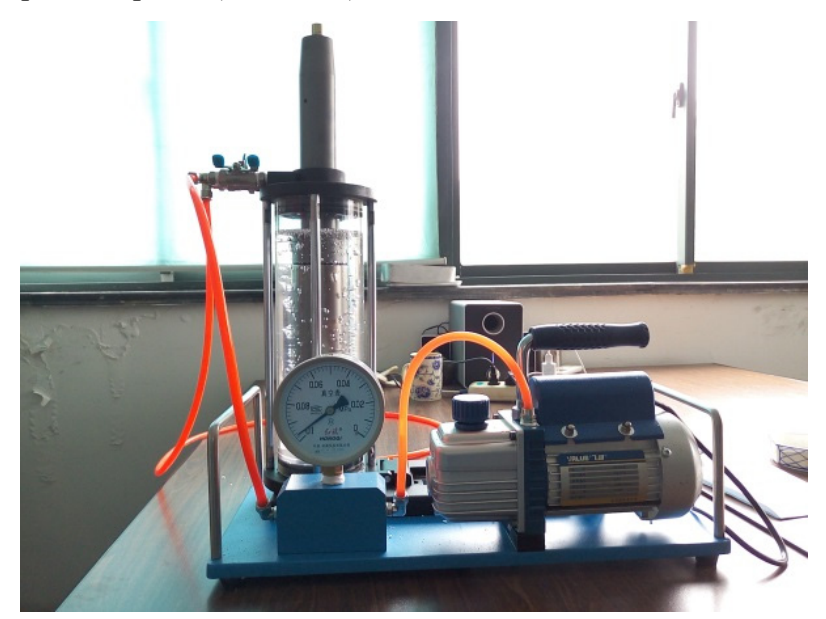

Fig 2. Vacuum saturation of pore pressure probe. 


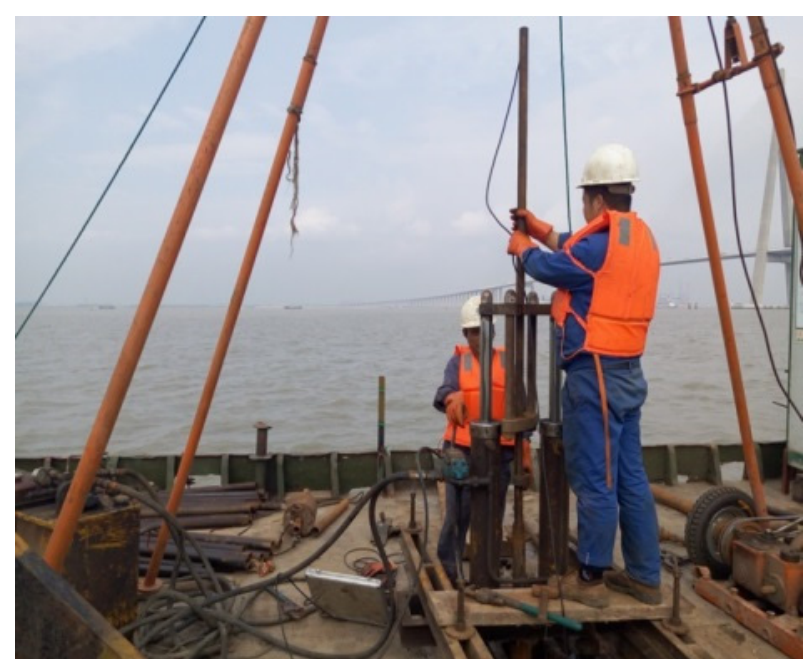

Fig 3. CPTU test site in water area.

\section{Analysis of measured data of water head of aquifer at river bottom}

The average number of vessels passing through the water area of the project is more than 2000 per day. In order to avoid the operation safety risk and realize the test purpose, a non channel area to the south of the maximum buried depth of the structure is selected, and the pore pressure dissipation function is used to carry out the dissipation of pore pressure at the top and bottom of the tunnel at $\mathrm{C} 1$ /

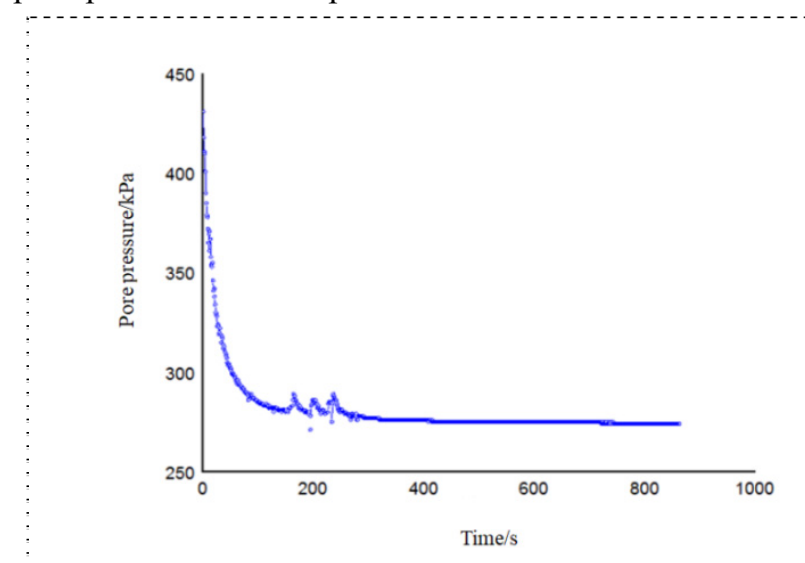

Fig 5. Pore pressure dissipation curve of tunnel top depth at $\mathrm{C} 1$ test point.

Pore pressure dissipation test at the top and bottom of the tunnel separately are also conducted at $\mathrm{C} 2$ test point. The tunnel top and bottom elevation are $-48.3 \mathrm{~m}$ and $60.3 \mathrm{~m}$, which are respectively located in the (5) 1 silty fine sand and (5) 2 fine sand layer. The dissipation curve is shown in Figure 7-8. According to the analysis of
C2 test points. The water head at this depth is measured. The longitudinal of tunnel and location of test holes are shown in Figure 4.

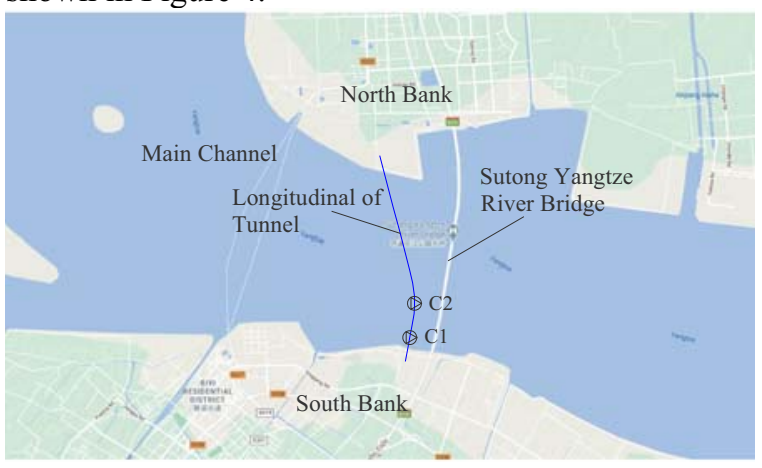

Fig 4. Longitudinal of tunnel and location of test holes.

Pore pressure dissipation test was conducted at the top and bottom of the tunnel of $\mathrm{C} 1$ test point separately. The elevation of the tunnel top and bottom was $-27.0 \mathrm{~m}$ and $38.0 \mathrm{~m}$, respectively, which were located in the (4) ${ }_{1}$ silty clay mixed silt and (4) 2 silty layer. The dissipation curve is shown in Figure 5-6. According to the analysis of the dissipation curve, the stratum at $-27.0 \mathrm{~m}$ contains a lot of cohesive soil, the test data include the excess pore water pressure caused by penetrating. The initial value of the pore water pressure is $686 \mathrm{kPa}$ and the stable value is $274 \mathrm{kPa}$ after 15 minutes of dissipation. The initial value of water pressure at $-38.0 \mathrm{~m}$ is $111 \mathrm{kPa}$, and the pore water pressure is stable at $386 \mathrm{kPa}$ after $12 \mathrm{~min}$ recovery.

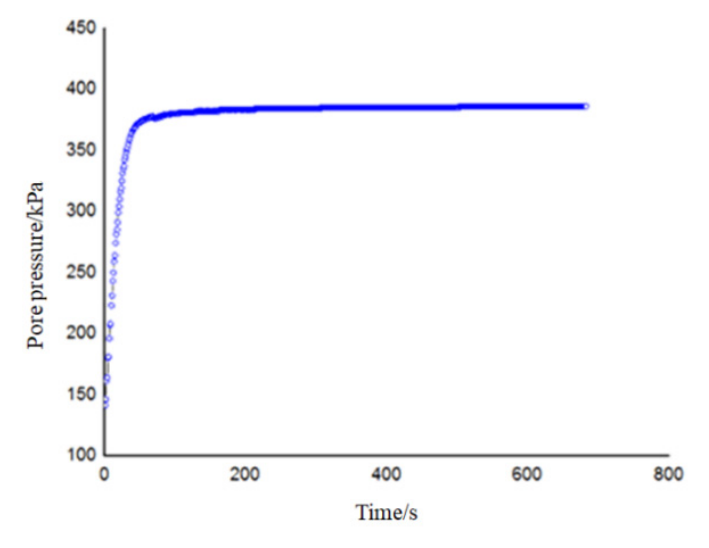

Fig 6. Pore pressure dissipation curve of tunnel bottom depth at $\mathrm{C} 1$ test point.

dissipation curve, the initial value of water pressure in silty sand layer at $-48.3 \mathrm{~m}$ of the tunnel top elevation is $213 \mathrm{kPa}$, and after 10 minutes of recovery, the pore water pressure value is stable at $471 \mathrm{kPa}$. The initial value of water pressure at $-60.3 \mathrm{~m}$ of the tunnel bottom elevation is $558 \mathrm{kPa}$, and the pore water pressure value is stable at $580 \mathrm{kPa}$ after $10 \mathrm{~min}$ recovery. 


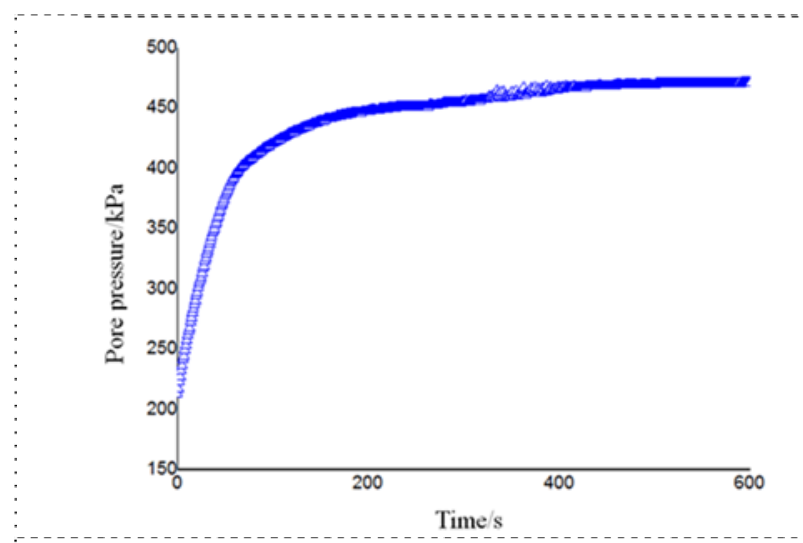

Fig 7. . Pore pressure dissipation curve of tunnel top depth at $\mathrm{C} 2$ test point.

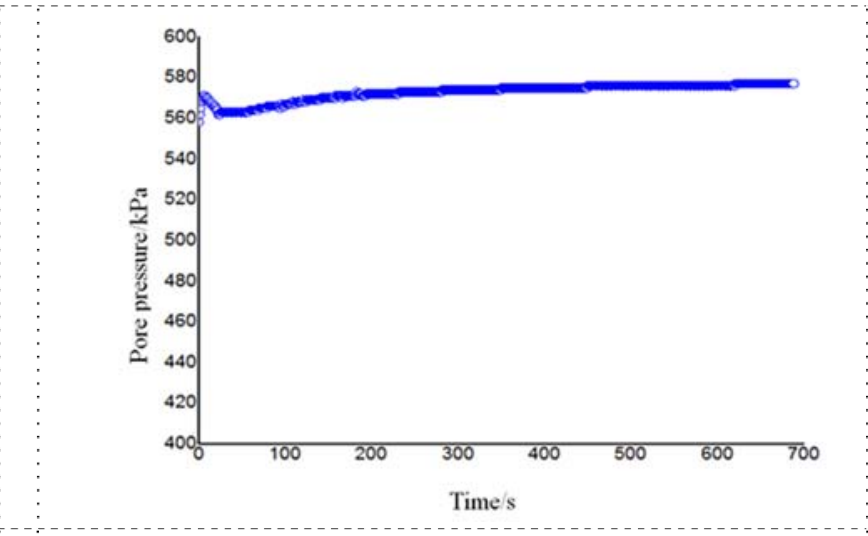

Fig 8. Pore pressure dissipation curve of tunnel bottom depth at $\mathrm{C} 2$ test point. Where

$H-$ head elevation,

$P$ — water head pressure,

$h$-elevation of test point.
The measured head pressure of CPTU is converted into head elevation according to the following formula (1), and the comparison with the measured results of land pumping test hydrological well is shown in Table 2.

$$
H=P / 10+h
$$

Table2. Comparison between CPTU measurement results and hydrological well measurement results.

\begin{tabular}{|c|c|c|c|c|}
\hline \multicolumn{4}{|c|}{ CPTU measurement results of water area } & \multirow{2}{*}{$\begin{array}{l}\text { Measurement results of land } \\
\text { hydrological wells } \\
\text { Aquifer head elevation }\end{array}$} \\
\hline Test point & Elevation of test point $(\mathrm{m})$ & Aquifer & $\begin{array}{l}\mathrm{H}(\text { Head elevation }) \\
(\mathrm{m})\end{array}$ & \\
\hline \multirow{2}{*}{ C1 } & -27.0 & (4) 1 & 0.4 & $-^{\mathrm{a}}$ \\
\hline & -38.0 & (4) 2 & 0.6 & $-0.80 \sim 0.30$ \\
\hline \multirow{2}{*}{$\mathrm{C2}$} & -48.3 & (5) 1 & -1.2 & $-1.20 \sim-0.10$ \\
\hline & -60.3 & (5) 2 & -2.3 & $-1.20 \sim-0.10$ \\
\hline
\end{tabular}

a Notes there is no data.

The above comparison shows that the groundwater head elevation measured by CPTU test in water area is basically consistent with that of confined water head measured by land hydrological well, which indicates that the method of in-situ layered measurement of water head pressure of river bottom aquifer by CPTU is feasible and reliable, which provides a successful solution for the quantitative measurement of underground water parameters of water area engineering. The water head elevation of each aquifer is basically consistent, which is verified that the aquifer is connected with each other. The water head elevation of each aquifer is basically consistent with the river surface elevation, which indicates that the groundwater in this tunnel has good connectivity with the Yangtze River water, and the river water level elevation can be used as the head height.

\section{Conclusions and suggestions}

In this paper, the CPTU probe is used to measure the water pressure of the aquifer at the bottom of the river. Compared with the water level and estimated water pressure of the land hydrological well, the method is accurate, efficient and economical, which provides the measured data support for the maximum water pressure of $0.8 \mathrm{MPa}$ of the project.
The traditional method of measuring groundwater level by hydrological well in water area is still mixed water level because it is difficult to guarantee the watertight effect. However, the CPTU scheme adopted in this paper can obtained groundwater pressure in different layers without water stop measures, which is worth popularizing widely.

The dissipation time of pore pressure in different soil layers is directly related to its permeability characteristics [7]. The determination of soil permeability coefficient based on CPTU is another important application of CPTU in groundwater exploration. In the follow-up, the research results of existing literature will be summarized, and the in-situ measurement of permeability coefficient by CPTU will be carried out.

\section{References}

1. National standards of the People's Republic of China. (2009) Code for investigation of geotechnical engineering. China Architecture \& Building Press, Beijing.

2. Gao D.Z. (2010) Geotechnical engineering investigation and design. China Communications Press, Beijing. 
3. Wang S.M. (2014) Application of CPTU in electric power engineering investigation. Site. Investig. Sci. Technol S1: 97-101.

4. Liu S.Y., Cai G.J., Zou H.F. (2013) Practical soil classification methods in China based on piezocone penetration tests. Chinese. J. Geotech. ENG 35:17651776.

5. Meng G.T., Zhang D.B., Liu C.Y.,et al. (2001) A contrastive study on the consolidation coefficient of soil obtained by piezocone penetration test and lab consolidation test. Hydrogeol. Eng. Geol 01:18-20.

6. Wang J.P., Xu Y.S., Ma L., Shen S.L. (2013) An approach to evaluate hydraulic conductivity of soil based on CPTU Test. Mar. Georesour. Geotec 31:242-253.

7. Wang J.P., Shen S.L.(2013) Determination of permeability coefficient of soil based on CPTU.Geotech. Mech 34:3335-3339. 